\title{
COMPARISONS OF METHODS FOR LOGATING OVA IN THE OVIDUCT OF THE RABBIT
}

\author{
W. J. LONGLEY* AND D. L. BLACK \\ Department of Veterinary and Animal Sciences, \\ University of Massachusetts, Amherst, Massachusetts, U.S.A.
}

(Received 3rd June 1967, revised 6th September 1967)

\begin{abstract}
Summary. A new technique for the location of ova in the rabbit oviduct is presented. The method consists of freezing the oviducts in situ immediately after killing the rabbits, and then removing and clearing them with benzyl-benzoate as described by Orsini (1962). The ova are located in the cleared oviducts under a dissecting microscope. The results obtained by this method are compared with the segmentation technique often used. When the position of ova in frozen-cleared oviducts was compared with the position of ova in segmented oviducts, ova were located approximately $10 \%$ further down the tube from 24 to $48 \mathrm{hr}$ post coitum, at the same position at $60 \mathrm{hr}$ and $10 \%$ closer to the ovarian end at $72 \mathrm{hr}$ than when the segmentation method was used. Clearing alone resulted in the ova being located intermediate to the other two methods. It was concluded that the method by which ova are located in the oviduct has considerable bearing on the results obtained.
\end{abstract}

\section{INTRODUCTION}

The movement of ova through the oviduct of the rabbit normally requires 3 to 4 days (Burdick \& Pincus, 1935; Greenwald, 1959, 1961; Harper, 1964, 1965; Harper, Bennett, Bournsnell \& Rowson, 1960). The rate of movement, however, is not uniform over the entire length of the oviduct (Chang \& Harper, 1966; Greenwald, 1959, 1961; Harper, 1961, 1964, 1965, 1966; Harper et al., 1960). In the rabbit, Greenwald (1961) found that ova moved through the ampullary region within $2 \mathrm{hr}$. Harper $(1961,1965,1966)$ observed that the time required to traverse the ampulla was $30 \mathrm{~min}$ or less. Greenwald (1961) also noted that ova were never found in the region near the tubo-uterine junction indicating that they moved through this area very rapidly. More extensive references may be found in Brundin (1965) and Chang \& Harper (1966).

The method most commonly used for locating ova in the oviduct has been to segment the oviduct and flush the segments to recover the ova (Anderson, 1927; Chang \& Harper, 1966; Greenwald, 1959, 1961; Harper, 1961). Harper (1964) and Harper et al. (1960) introduced radio-active gold resin spheres into the oviduct and followed their movement. The position of the spheres was deter-

* Present address: Department of Physiology and Biophysics, Dalhousie University, Halifax, Nova Scotia, Canada. 
mined by an autoradiograph of the oviduct after removal from the rabbit. These 'artificial eggs' moved in a fashion quite similar to that of normal ova with the exception of a few which stuck at the ovarian end. Also, Harper $(1965,1966)$ transferred toluidine blue-stained ova to the oviducts of rabbits and visually followed their movement through the ampullary region. This technique does not lend itself to a study of movement through the entire oviduct as the thick musculature of the isthmus prevents visual observation of the stained ova.

The experiments reported here were undertaken to determine if the method of locating ova in the oviduct of the rabbit had any influence on the results obtained.

\section{MATERIALS AND METHODS}

Sixty virgin female rabbits of the New Zealand White strain, weighing between 3.5 and $4.8 \mathrm{~kg}$, were used in the experiments. All were mated to males of known fertility and killed with an overdose of sodium pentobarbital at five different times post coitum (p.c.): 24, 36, 48, 60 and $72 \mathrm{hr}$. Three methods of locating ova were compared at each of the time intervals by killing four animals/time method group.

The first method of locating ova was the segmentation method. The animals were killed at the prescribed times p.c. and their oviducts immediately removed and placed in physiological saline. The oviducts were trimmed of excess tissue and cut into ten equal segments. Each segment was flushed with physiological saline from both ends. The saline flushing fluid was caught in a watch glass and viewed under a dissecting microscope for the presence of ova. The number of ova from each segment was recorded and expressed as a percentage of the total length. The percentage value was recorded as the half-way point of each segment. For example, ova found in segment 6 (number 1 being closest to the ovarian end) were noted as being at $55 \%$ of the total distance.

In the second method, the oviducts were removed and trimmed as above and then they were fixed and cleared by the benzyl-benzoate method of Orsini (1962). After clearing, the oviducts were viewed under a dissecting microscope and the location of each ovum recorded by measuring the actual distance they were from the ovarian end of the oviduct. This position was expressed as a percentage of the total length of the oviduct.

The third technique was similar to the clearing technique except that, following killing, the oviducts were immediately exposed by a mid-ventral incision and 2-methyl-butane, cooled to the temperature of liquid nitrogen, was poured over the exposed oviducts. The oviducts were solidly frozen within $1 \mathrm{~min}$ from the time of sodium pentobarbital injection. After a period of approximately $5 \mathrm{~min}$, the oviducts were thawed, removed and cleared as above. It is believed that freezing stops all muscular activity immediately, while with the other techniques activity may continue for some time.

The data was analysed as a split-plot design by analysis of variance, and broken down into individual degrees of freedom and orthogonal comparisons made. 


\section{RESULTS}

The mean distance at which ova were located was determined at each of five time intervals and for each method. Data obtained are shown in Table 1. The difference resulting from methods was not significant. There was, however, difference due to time (significant at $P \leqslant 0.01$ ). This difference can be attributed to a movement of ova through the oviduct which was linear with respect to time between 24 and $72 \mathrm{hr}$ p.c. (as noted by statistical analysis). Interaction of significant magnitude $(P \leqslant 0.01)$ occurred between method and time. This significant interaction results because ova recovered by the segmentation method were nearer the ovarian end of the tube than those located by the other methods up to $60 \mathrm{hr}$ p.c. At $72 \mathrm{hr}$ p.c., however, ova located by the segmentation method had moved further, while at $60 \mathrm{hr}$ p.c. all three methods gave essentially

TABLE 1

THE POSITION OF OVA IN THE OVIDUCT IN RELATION TO TIME post coitum AS DETERMINED BY THREE LOCATION METHODS*

\begin{tabular}{c|c|c|c}
\hline \multirow{3}{*}{ Time p.c. $(h r)$} & \multicolumn{3}{|c}{ Method of locating ova } \\
\cline { 2 - 4 } & $I(\%)$ & $I I(\%)$ & $I I I(\%)$ \\
\hline 24 & 54.4 & 58.8 & 62.7 \\
36 & 61.6 & 69.3 & 74.8 \\
48 & 65.5 & 71.2 & 75.3 \\
60 & 76.5 & 77.9 & 77.4 \\
72 & $92 \cdot 1$ & 86.9 & 82.7 \\
\hline
\end{tabular}

* Method I: segmentation of the oviduct; method II: clearing; method III: freezing and clearing.

the same results. Clearing without freezing resulted in location of ova at a position about midway between those of the segmentation method and those of the freezing and clearing method. These data indicate that the method used for locating ova can have significant effect upon the results obtained unless the time under study is approximately $60 \mathrm{hr}$ after mating.

The recovery of ova by the segmentation method was $93.7 \%$. This is based on the number of ova recovered compared to the number of ovulation spots noted on the corresponding ovaries. The recovery rate for the other two methods was $99 \cdot 7 \%$.

\section{DISGUSSION}

The position of ova in the oviduct when determined by the segmentation method is quite similar to that noted by Harper (1964), Harper et al. (1960) and Greenwald $(1959,1961)$. However, the ova located by the freezing and clearing method were about $10 \%$ further down the tube than those located by the segmentation method up to $48 \mathrm{hr}$ p.c. and approximately $10 \%$ less at $72 \mathrm{hr}$ p.c., while at $60 \mathrm{hr}$ they are the same. This would indicate that the ova move in a definite direction after the animal is killed. It would appear that they move 
back toward the ovarian end until about $60 \mathrm{hr}$ p.c. and then move toward the uterine end. The movement of ova in the oviducts which were cleared only, appears to be less. The reason for this is probably twofold: firstly, the accuracy of positioning is improved and, secondly, the time required to process the oviducts before fixing is less than for segmentation. These data, as well as other observations in our laboratory, indicate that the freezing of the oviducts results in holding the ova at a position which approximates more nearly their position at the time the animal was killed. Greenwald $(1959,1961)$ and Harper et al. (1960) have observed that ova move through the rabbit oviduct at a faster rate from 60 to $72 \mathrm{hr}$ p.c. as compared to the rate between 24 and $48 \mathrm{hr}$ p.c. The results indicate that this is in part justified but that the method of segmentation tends to exaggerate this difference.

\section{ACKNOWLEDGMENTS}

This work is part of a dissertation submitted by the senior author to the Graduate School, University of Massachusetts, in partial fulfilment of the $\mathrm{Ph} . \mathrm{D}$. degree, and was supported by a National Institute of Health Grant H D00745.

\section{REFERENCES}

ANDERson, D. (1927) The rate of passage of the mammalian ovum through various portions of the fallopian tube. Am. F. Physiol. 82, 557.

BRUndin, J. (1965) Distribution and function of adrenergic nerves in the rabbit fallopian tube. Acta physiol. scand. 66, Suppl. 259.

Burdick, H. O. \& Pincus, G. (1935) The effect of oestrin injections upon the developing ova of mice and rabbits. Am. F. Physiol. 111, 201.

Chang, M. C. \& HARPER, M. J. K. (1966) Effects of ethinyl estradiol on egg transport and development in the rabbit. Endocrinology, 78, 860 .

Greenwald, G. S. (1959) Tubal transport of ova in the rabbit. Anat. Rec. 133, 386.

GREENWALd, G. S. (1961) A study of the transport of ova through the rabbit oviduct. Fert. Steril. 12, 80.

HARPER, M. J. K. (1961) The mechanisms involved in the movement of newly ovulated eggs through the ampulla of the rabbit fallopian tube. F. Reprod. Fert. 2, 522.

HARPER, M. J. K. (1964) The effects of constant doses of oestrogen and progesterone on the transport of artificial eggs through the reproductive tract of ovariectomized rabbits. F. Endocr. 30, 1.

Harper, M. J. K. (1965) Transport of eggs in cumulus through the ampulla of the rabbit oviduct in relation to day of pseudopregnancy. Endocrinology, 77, 114.

HARPER, M. J. K. (1966) Hormonal control of transport of eggs in cumulus through the ampulla of the rabbit oviduct. Endocrinology, 78, 568.

Harper, M. J. K., Bennett, J. P., Bournsnell, J. C. \& Rowson, L. E. A. (1960) An autoradiographic method for the study of egg transport in the rabbit fallopian tube. $\mathcal{F}$. Reprod. Fert. 1, 249.

Orsini, M. W. (1962) Technique of preparation study and photography of benzyl-benzoate cleared material for embryological studies. F. Reprod. Fert. 3, 283. 